\title{
Consumo de nutrientes e desempenho de cordeiros em confinamento alimentados com dietas com polpa cítrica úmida prensada em substituição à silagem de milho ${ }^{1}$
}

\author{
Mykel Stefanni Pereira², Edson Luis de Azambuja Ribeiro ${ }^{3}, 4$, Ivone Yurika Mizubuti ${ }^{3}$ 4, Marco \\ Antonio da Rocha ${ }^{3}$, Juliana Tiemi Kuraoka ${ }^{5}$, Eduardo Yukio Okada Nakaghi ${ }^{6}$
}

\author{
${ }^{1}$ Projeto financiado pelo CNPq. \\ 2 Programa de Pós-graduação em Ciência Animal - UEL, Londrina, PR. \\ ${ }^{3}$ Departamento de Zootecnia - UEL, Londrina, PR. \\ ${ }^{4}$ Bolsista do CNPq. \\ ${ }^{5}$ Bolsista de aperfeiçoamento - UEL. \\ ${ }^{6}$ Curso de graduação em MedicinaVeterinária - UEL. Bolsista de Iniciação Científica.
}

\begin{abstract}
RESUMO - Objetivou-se com este trabalho avaliar o efeito da substituição da silagem de milho pela polpa cítrica úmida prensada (PCUP) no desempenho de cordeiros da raça Santa Inês. Vinte e quatro cordeiros com 90 dias de idade e 18,44 kg PV inicial médio foram confinados durante 67 dias e alimentados com dietas contendo níveis crescentes de PCUP em substituição à silagem de milho (0, 25, 50 e 75\% MS). Não houve diferença para ingestão de MS (IMS). Os valores médios de IMS em g, \%PV e g/kgPV 0,75 foram respectivamente, 1.180, 4,74 e 126. Houve redução linear na ingestão de FDN, em \%PV e em $\mathrm{g} / \mathrm{kgPV}^{0,75}$, com o aumento dos níveis de substituição. A ingestão de PB não foi afetada pela dieta. Verificou-se aumento linear para a ingestão de $\mathrm{EE}$, em \%PV e em g/kgPV,75, e para a FDA, em \%PV. A ingestão de carboidratos não-fibrosos (CNF) apresentou comportamento quadrático, em \%PV e em g/kgPV 0,75 , e linear em g/animal.dia, à medida que houve a substituição da silagem de milho pela PCUP. A substituição da silagem de milho pela PCUP não afetou a conversão alimentar (4,33 kg MS/ kg de ganho), no entanto, o ganho de peso médio apresentou comportamento quadrático em função do nível de substituição; o nível de substituição de 48\% promoveu o maior ganho médio diário. Os resultados sugerem que a PCUP pode substituir a silagem de milho em dietas para cordeiros em confinamento.
\end{abstract}

Palavras-chave: conversão alimentar, ganho de peso, laranja, ovinos

\section{Nutrient intake and performance of lambs in feedlot fed diets with different levels of pressed citrus pulp in substitution of corn silage}

\begin{abstract}
This experiment was carried out to evaluate the substitution of corn silage by fresh pressed citrus pulp (FPCP) on the performance of Santa Ines lambs. Twenty-four lambs, with average age of 90 days and initial average body weight of $18.44 \mathrm{~kg}$, were feedlot during 67 days and fed with increasing levels of FPCP in substitution of corn silage $(0,25$, 50, and $75 \% \mathrm{DM})$. There was no difference for DM intake (DMI). The average values for DMI in $\mathrm{g}$, \%BW and $\mathrm{g} / \mathrm{kgBW}^{0.75}$ were, respectively, 1,180, 4.74 and 126. There was a linear decreased in NDF intake, in \%BW and g/kgBW ${ }^{0.75}$, with the increase of the level of substitution. The CP intake was not affected by the diet. There was linear increase for EE intake, in \%BW and $\mathrm{g} / \mathrm{kgBW}^{0.75}$, and for ADF in \%BW. The non fiber carbohydrate intake showed quadratic behavior, in \%BW and g/kgBW ${ }^{0.75}$ and linear increase in g/an/day, as corn silage was substituted by FPCP. The substitution of corn silage by FPCP did not affect the feed conversion (4.33 kg DM/kg of gain), however, the average weight gain showed a quadratic behavior in function of substitution level. The level of substitution of $48 \%$ promoted the highest average daily gain. The results suggest that FPCP can substitute corn silage in the diets for lambs in feedlot confined.
\end{abstract}

Key Words: feed conversion, orange, sheep, weight gain

\section{Introdução}

Ultimamente, tem-se notado interesse em intensificar a terminação de cordeiros objetivando rapidezna comercialização e produção de carcaças de melhor qualidade (Garcia et al.,
2000). O confinamento é uma alternativa que possibilita a produção de carne de cordeiro com maior rapidez ao mesmo tempo que facilita o controle de verminose, uma vez que os animais não têm contato com as pastagens, principal fonte de contaminação (Reis et al., 2001). Todavia, este tipo de 
criação requer maior investimento com instalações, alimentação e mão-de-obra. Uma das formas de viabilizar este sistema é a utilização de rações formuladas com alimentos alternativos disponíveis em cada região.

O Brasil possui grande diversidade de culturas agrícolas que geram grande volume de produção nas diferentes regiões do País. O processamento de diversos produtos origina altas quantidades de resíduos, que, na maioria das vezes, podem ser aproveitados na alimentação animal, reduzindo a contaminação ambiental e, ao mesmo tempo, os custos de produção animal, uma vez que a alimentação corresponde a 60-70\% desses custos (Dutra et al., 1997).

A indústria de suco de laranja produz como subproduto o bagaço de laranja, que corresponde a 50\% do total da fruta; seu valor na alimentação de ruminantes é semelhante ao dos grãos, pois possui alta digestibilidade (Van Soest, 1994; Silva et al., 1997). A polpa cítrica tem sido utilizada na alimentação animal na forma peletizada (PCP), pois apresenta excelente valor energético e alta digestibilidade da fração fibrosa (Porcionato et al., 2004). Em virtude do elevado custo de secagem, têm-se buscado alternativas para utilização do bagaço cítrico úmido, entre elas, a conservação na forma de silagem (Ashbell \& Donahaye, 1984; Silva et al., 1997; Ítavo et al., 2000a,b). Outra forma de utilização é a polpa cítrica úmida prensada (PCUP), um produto intermediário entre o bagaço de laranja e a PCP. O processo básico de produção da PCUP consiste na adição de óxido ou hidróxido de cálcio, seguida de moagem e prensagem do bagaço de laranja. Embora a PCUP passe por um processo de desidratação, o teor de MS do produto final é de aproximadamente 25\% (Pereira et al., 2005). Objetivou-se com este trabalho avaliar o efeito da substituição da silagem de milho pela polpa cítrica úmida prensada sobre o consumo de nutrientes e o desempenho de cordeiros em confinamento.

\section{Material e Métodos}

O experimento foi realizado no Setor de Ovinocultura do Departamento de Zootecnia da Universidade Estadual de Londrina (UEL), Londrina, PR, durante o período de setembro a novembro de 2004. Foram utilizados 24 cordeiros Santa Inês, machos não-castrados, com 90 dias de idade e peso vivo inicial de 18,44 $\pm 1,1 \mathrm{~kg}$.

Os animais foram confinados em baias cobertas, suspensas, com piso de madeira ripado. Previamente ao início do experimento, os cordeiros foram everminados e vacinados contra clostridioses.

A polpa cítrica úmida prensada (PCUP) foi adquirida da COROL Citrus, situada na cidade de Rolândia, PR. O subproduto (Tabela 1) foi obtido a cada 10-15 dias e armazenado em baldes plásticos (100 L) até sua utilização.

As dietas experimentais, isoprotéicas e isoenergéticas, foram formuladas para atender às exigências nutricionais de cordeiros de porte médio e ganho de peso estimado em 250 g/dia, com base no NRC (1985) (Tabela 2). A alimentação foi dividida em duas refeições, fornecidas às $7 \mathrm{~h} 30$ e às $17 \mathrm{~h}$. Os ingredientes volumosos e o concentrado eram misturados no cocho no momento da alimentação. A cada refeição, foram recolhidas e pesadas as sobras de alimento para ajuste da quantidade ofertada e cálculo do consumo de MS. As sobras eram mantidas em torno de $15 \%$ do total ofertado. Uma amostra das sobras diárias, da silagem de milho e da PUCP era

Tabela 1 - Composição nutricional (\% MS) dos ingredientes das dietas experimentais

\begin{tabular}{lrrrr}
\hline \multirow{2}{*}{ Nutriente } & \multicolumn{4}{c}{ Ingrediente } \\
\cline { 2 - 5 } & PCUP & $\begin{array}{c}\text { Silagem de } \\
\text { milho }\end{array}$ & Milho grão & \multicolumn{1}{c}{$\begin{array}{c}\text { Farelo de } \\
\text { soja }\end{array}$} \\
\hline MS & 24,41 & 31,88 & 87,63 & 88,69 \\
MO & 93,91 & 95,22 & 98,71 & 93,02 \\
PB & 7,44 & 7,09 & 7,95 & 46,92 \\
EE & 3,24 & 2,51 & 3,46 & 1,78 \\
FDN & 34,46 & 59,38 & 24,63 & 14,21 \\
FDA & 33,00 & 33,09 & 4,45 & 10,25 \\
FB & 16,79 & 26,08 & 3,11 & 6,45 \\
CT & 83,23 & 85,62 & 87,31 & 44,32 \\
CNF & 48,78 & 26,24 & 62,68 & 30,11 \\
Cinzas & 6,09 & 4,78 & 1,29 & 6,99 \\
NDT & 71,36 & 63,70 & 79,90 & 81,67 \\
\hline
\end{tabular}

PCUP = polpa cítrica úmida prensada; $\mathrm{CT}=$ carboidratos totais .

Tabela 2 - Composição percentual dos ingredientes e nutricional das dietas experimentais (\% MS)

\begin{tabular}{lcccc}
\hline \multirow{2}{*}{ tem } & \multicolumn{4}{c}{ Nível de polpa cítrica $(\%)$} \\
\cline { 2 - 5 } & 0 & 25 & 50 & 75 \\
\hline
\end{tabular}

Ingrediente

\begin{tabular}{lrrrr} 
PCUP & 0,00 & 15,00 & 30,00 & 45,00 \\
Silagem de milho & 60,00 & 45,00 & 30,00 & 15,00 \\
Milho grão & 20,00 & 20,00 & 20,00 & 20,00 \\
Farelo de soja & 19,75 & 19,75 & 19,75 & 19,75 \\
Mistura mineral & 0,25 & 0,25 & 0,25 & 0,25 \\
\hline Composição nutricional & & & & \\
\hline MS & 54,29 & 53,17 & 52,05 & 50,93 \\
MO & 95,25 & 95,05 & 95,85 & 94,66 \\
PB & 15,11 & 15,16 & 15,20 & 15,27 \\
EE & 2,54 & 2,67 & 2,76 & 2,88 \\
FDN & 43,36 & 39,62 & 35,88 & 32,15 \\
FDA & 22,77 & 22,75 & 22,74 & 22,73 \\
CT & 77,59 & 77,23 & 76,87 & 76,51 \\
CNF & 34,23 & 37,61 & 40,99 & 44,36 \\
Cinzas & 4,75 & 4,95 & 5,15 & 5,34 \\
NDT & 70,34 & 71,48 & 72,62 & 73,76 \\
\hline
\end{tabular}

PCUP = polpa cítrica úmida prensada $; \mathrm{CT}=$ carboidratos totais. 
congelada para posteriores análises. As amostras de milho e farelo de soja foram coletadas no momento do preparo das rações. Para obtenção das amostras compostas, o conjunto das amostras diárias de cada semana foi homogeneizado para retirada de uma amostra.

As análises dos teores de MS, MO, PB, EE, FDN e FDA foram feitas segundo Silva (1990). Os carboidratos totais (CT) e os CNF foram calculados segundo Sniffen et al. (1992) e os nutrientes digestíveis totais (NDT), segundo Kearl (1982). As análises químico-bromatológicas foram realizadas no Laboratório de Nutrição Animal da Universidade Estadual de Londrina.

O delineamento experimental foi o inteiramente casualizado com 24 animais e quatro tratamentos. Os tratamentos experimentais consistiram de quatro níveis $(0,25,50$ e 75\% da MS) de substituição da silagem de milho por PCUP. O período total de confinamento foi de 67 dias, de modo que os primeiros 14 dias foram destinados à adaptação dos animais às instalações e à dieta alimentar. Os animais foram pesados semanalmente, sempre após jejum alimentar de 16 horas, para acompanhamento da evolução do peso e do ganho de peso diário.

Foram calculados os custos da utilização de PCUP em substituição à silagem de milho. No entanto, foram considerados na análise apenas os custos relacionados à dieta, pois os outros fatores, como instalações e mão-de-obra, foram os mesmos em todos os tratamentos. Os dados obtidos foram submetidos à análise de regressão por meio de um modelo inteiramente casualizado, tendo como variável independente os níveis de substituição da silagem de milho pela PCUP, utilizando-se o pacote estatístico SAS (1994).

\section{Resultados e Discussão}

As ingestões de MS e MO, nas diferentes formas de expressão, não foram afetadas ( $\mathrm{P}>0,05)$ pela dieta (Tabela 3 ). Apesar de a ingestão de MS, avaliada em \%PV, não ter sido influenciada $(\mathrm{P}=0,057)$ pelos níveis de polpa cítrica na dieta, numericamente, houve aumento na ingestão até o nível de 50\% de substituição e, em seguida, um declínio na ingestão no nível de 75\%, o que representa um comportamento quadrático. Esse tipo de comportamento (quadrático) foi semelhante aos verificados por Ítavo et al. (2000a) ao avaliarem o efeito da substituição da silagem de milho pelo bagaço de laranja na alimentação de vacas leiteiras. Allen (2000) relatou que, ao promover mudanças no teor de FDN da dieta por meio da substituição de forragem por alimentos concentrados, espera-se que a ingestão de MS tenha comportamento quadrático. Nesse caso, o consumo aumenta em virtude da redução da limitação física dos compartimentos gastrintestinais, caracterizada pelo enchimento do rúmenretículo, até a ocorrência de consumo excessivo de energia, que promove o controle do consumo pelo mecanismo metabólico.

A ingestão de MS pode também estar relacionada à menor aceitabilidade dos animais à dieta com elevado teor de polpa cítrica. Henrique et al. (1998) verificaram que, quando a polpa cítrica foi adicionada em grande quantidade na dieta (55\% na MS) de bovinos em confinamento, houve redução da ingestão de MS e conseqüente redução no ganho de peso.

A ingestão média de MS foi de $126 \mathrm{~g} / \mathrm{kg}^{0,75}$, superior à encontrado por Furusho-Garcia et al. (2004), de 76,2 g/kg0,75, para cordeiros Santa Inês alimentados com dieta composta de $80 \%$ de concentrado e $20 \%$ de feno de coastcross. Os valores de ingestão de MS também foram superiores aos verificados por Véras et al. (2005), de $97 \mathrm{~g} / \mathrm{kg}^{0,75}$ e 4,24\% PV, respectivamente, no entanto, foram semelhantes quando os consumos foram avaliados em g/animal/dia (1.150 g).

O consumo de FDN, segundo Waldo (1986), é o melhor e mais simples fator para predizer o consumo voluntário de MS pelos ruminantes. Mertens (1992) comentou que a FDN expressa melhor a propriedade dos alimentos em ocupar espaços que os componentes fibra bruta e FDA. A ingestão

Tabela 3 - Ingestão de MS e MO em cordeiros alimentados com dietas contendo polpa cítrica úmida prensada em substituição à silagem de milho

\begin{tabular}{|c|c|c|c|c|c|c|}
\hline Item & \multicolumn{4}{|c|}{ Nível de polpa cítrica $(\%)^{1}$} & CV (\%) & Regressão \\
\hline MS (g/dia) & 1.098 & 1.159 & 1.289 & 1.173 & 11,12 & $\hat{\mathrm{Y}}=1.180$ \\
\hline MS (\% PV) & 4,60 & 4,69 & 4,91 & 4,76 & 2,36 & $\hat{\mathrm{Y}}=4,74$ \\
\hline MS $\left(g / \mathrm{kgPV}^{0,75}\right)$ & 121 & 124 & 132 & 126 & 3,36 & $\hat{\mathrm{Y}}=126$ \\
\hline MO (g/dia) & 1.050 & 1.107 & 1.222 & 1.101 & 11,76 & $\hat{\mathrm{Y}}=1.120$ \\
\hline MO $\left(g / \mathrm{kg}^{0,75}\right)$ & 116 & 119 & 125 & 118 & 4,31 & $\hat{\mathrm{Y}}=119$ \\
\hline
\end{tabular}


de FDN neste estudo (Tabela 4) diferiu significativamente $(\mathrm{P}<0,05)$ entre os tratamentos quando calculada em \%PV e em $\mathrm{g} / \mathrm{kgPV}^{0,75}$, mas não apresentou diferença $(\mathrm{P}>0,05)$ quando estimada em g/animal/dia. Tanto em \%PV quanto em $\mathrm{g} / \mathrm{kgPV}^{0,75}$, a ingestão de FDN teve redução linear de acordo com os níveis de substituição. Esta redução pode ser atribuída à composição das dietas, uma vez que houve redução gradativa de FDN das dietas à medida que se substituiu a silagem de milho pela polpa cítrica.

Os valores médios de ingestão de FDN em \%PV foram superiores aos citados por Van Soest (1994), de 0,8 e 1,2\% $\mathrm{PV}$, para bovinos de raça leiteira. No entanto, este mesmo autor sugeriu que os animais tendem a ultrapassar este limite quando a dieta apresenta baixos níveis de energia e buscam compensar a deficiência dietética. Esse comportamento foi bem evidenciado por Camurça et al. (2002), que encontraram valor de ingestão de FDN de 1,97\% PV em estudo com dietas contendo baixos níveis de energia e altos níveis de FDN.

O controle da ingestão de MS nos animais alimentados com as dietas com 0, 25 e 50\% de substituição da silagem de milho pela polpa cítrica provavelmente resultou do enchimento dos compartimentos gastrintestinais, representado pelas altas ingestões de FDN, tanto em \% PV quanto em $\mathrm{g} / \mathrm{kgPV}^{0,75}$. Entretanto, o maior ou menor limite de consumo de FDN deve estar relacionado, além das características dos animais, à qualidade da FDN das dietas. Ben-Ghedalia et al. (1989) verificaram alta digestibilidade da FDN da dieta contendo polpa cítrica quando avaliaram o efeito do amido ou da pectina sobre a digestão de ovinos. Esses autores atribuíram esse efeito à qualidade da parede celular da polpa cítrica.

Entre os nutrientes avaliados em g/dia, apenas a ingestão de CNF diferiu significativamente $(\mathrm{P}<0,05)$ entre as dietas e aumentou linearmente com a substituição da silagem de milho pela polpa cítrica (Tabela 4). Esse resultado pode ser atribuído à composição química das dietas. Houve diferença significativa para as ingestões de EE, FDA e CNF em \% PV e para as ingestões de EE e CNF em g $/ \mathrm{kg}^{0,75}$. Houve aumento linear para a ingestão de EE em \%PV e em g/ $/ \mathrm{kg}^{0,75}$ e para a ingestão de FDA em \%PV. Esse comportamento na ingestão de EE pode ser atribuído à composição química das dietas. A ingestão de CNF em \%PV e em g/kg0,75 apresentou comportamento quadrático, provavelmente em virtude da variação na composição das dietas e de uma possível variação na ingestão de MS.

Não houve diferença significativa para peso final e conversão alimentar (Tabela 5). O ganho de peso médio diário apresentou comportamento quadrático e o ganho de peso foi maior nos animais do tratamento com 50\% de

Tabela 4 - Ingestão de nutrientes em cordeiros alimentados com dietas contendo polpa cítrica úmida prensada em substituição à silagem de milho

\begin{tabular}{|c|c|c|c|c|c|c|c|}
\hline \multirow[t]{2}{*}{ Nutriente } & \multicolumn{4}{|c|}{ Nível de polpa cítrica $(\%)^{1}$} & \multirow[t]{2}{*}{ CV (\%) } & \multirow[t]{2}{*}{ Regressão } & \multirow[t]{2}{*}{$\mathrm{R}^{2}$} \\
\hline & 0 & 25 & 50 & 75 & & & \\
\hline PB (g/dia) & 179 & 187 & 205 & 183 & 11,04 & $\hat{\mathrm{Y}}=189$ & - \\
\hline PB (\% PV) & 0,75 & 0,76 & 0,78 & 0,74 & 2,79 & $\hat{\mathrm{Y}}=0,76$ & - \\
\hline PB $\left(g / \mathrm{kg}^{0,75}\right)$ & 20 & 20 & 21 & 20 & 3,65 & $\hat{\mathrm{Y}}=20$ & - \\
\hline EE (g/dia) & 30 & 33 & 38 & 34 & 11,18 & $\hat{\mathrm{Y}}=34$ & - \\
\hline EE (\% PV) & 0,13 & 0,14 & 0,14 & 0,14 & 3,01 & $\hat{Y}=0,13007+0,00015715 * X$ & 0,45 \\
\hline $\mathrm{EE}\left(\mathrm{g} / \mathrm{kg}^{0,75}\right)$ & 3,4 & 3,6 & 3,9 & 3,7 & 3,79 & $\hat{\mathrm{Y}}=3,43+0,00472 * \mathrm{X}$ & 0,40 \\
\hline FDN (g/dia) & 439 & 422 & 424 & 368 & 12,39 & $\hat{\mathrm{Y}}=414$ & - \\
\hline FDN (\% PV) & 1,84 & 1,71 & 1,62 & 1,49 & 3,51 & $\hat{\mathrm{Y}}=1,83752-0,00461 * \mathrm{X}$ & 0,88 \\
\hline $\mathrm{FDN}\left(\mathrm{g} / \mathrm{kgPV}^{0,75}\right)$ & 48 & 45 & 43 & 39 & 5,12 & $\hat{\mathrm{Y}}=48,46-0,11467 * \mathrm{X}$ & 0,75 \\
\hline FDA (g/dia) & 220 & 239 & 273 & 257 & 13,99 & $\hat{\mathrm{Y}}=247$ & - \\
\hline FDA (\% PV) & 0,92 & 0,96 & 1,04 & 1,04 & 4,39 & $\hat{Y}=0,92833+0,00169 * X$ & 0,60 \\
\hline FDA $\left(\mathrm{g} / \mathrm{kg}^{0,75}\right)$ & 24 & 26 & 28 & 28 & 6,28 & $\hat{\mathrm{Y}}=26$ & - \\
\hline CT (g/dia) & 839 & 887 & 981 & 883 & 11,97 & $\hat{\mathrm{Y}}=897$ & - \\
\hline CT (\% PV) & 3,52 & 3,59 & 3,73 & 3,58 & 3,18 & $\hat{\mathrm{Y}}=3,60$ & - \\
\hline CT $\left(\mathrm{g} / \mathrm{kg}^{0,75}\right)$ & 93 & 95 & 100 & 95 & 4,51 & $\hat{\mathrm{Y}}=96$ & - \\
\hline CNF (g/dia) & 401 & 465 & 556 & 515 & 11,71 & $\hat{\mathrm{Y}}=419,41+1,73 * X$ & 0,43 \\
\hline CNF (\% PV) & 1,68 & 1,88 & 2,12 & 2,08 & 3,22 & $\hat{Y}=1,67083+0,01259 * X-0,00009142 * X^{2}$ & 0,89 \\
\hline CNF (g/kg $\left.{ }^{0,75}\right)$ & 44 & 50 & 57 & 55 & 4,17 & $\hat{Y}=43,76+0,3793 * X-0,00293 * X^{2}$ & 0,84 \\
\hline
\end{tabular}

$\mathrm{CT}=$ carboidratos totais . 
Tabela 5 - Desempenho de cordeiros em confinamento alimentados com dietas contendo polpa cítrica úmida prensada em substituição à silagem de milho

\begin{tabular}{|c|c|c|c|c|c|c|c|}
\hline \multirow[t]{2}{*}{ Item } & \multicolumn{4}{|c|}{ Nível de polpa cítrica (\%) } & \multirow[t]{2}{*}{ CV (\%) } & \multirow[t]{2}{*}{ Regressão } & \multirow[t]{2}{*}{$\mathrm{R}^{2}$} \\
\hline & 0 & 25 & 50 & 75 & & & \\
\hline Peso inicial, kg & 18,74 & 18,05 & 18,82 & 18,15 & 14,62 & $\hat{\mathrm{Y}}=18,42$ & - \\
\hline Peso final, kg & 31,70 & 32,42 & 34,97 & 32,65 & 9,26 & $\hat{\mathrm{Y}}=32,98$ & - \\
\hline Ganho médio diário, g & 245 & 271 & 305 & 274 & 10,00 & $\hat{Y}=240,26+2,24 * X-0,02335 * X^{2}$ & 0,35 \\
\hline $\begin{array}{l}\text { Conversão alimentar } \\
\text { (kg de MS/kg de ganho) }\end{array}$ & 4,45 & 4,24 & 4,26 & 4,43 & 11,00 & $\hat{\mathrm{Y}}=4,33$ & - \\
\hline
\end{tabular}

substituição, o que comprova efeito positivo da inclusão de polpa cítrica na dieta. O nível de substituição de $48 \%$ foi o ponto de máxima da curva de regressão.

Dois aspectos são fundamentais para explicar este resultado: um está relacionado à ingestão de MS e o outro à característica das dietas. Os níveis crescentes de substituição da silagem de milho pela polpa cítrica caracterizam-se por redução gradativa no teor de FDN das dietas. Quando isso ocorre, espera-se que a ingestão de MS apresente comportamento quadrático (Allen, 2000) e que as diferenças em ingestão ocasionem 60 a 90\% das variações no desempenho animal (Mertens, 1994). Outro aspecto importante no desempenho de animais quando utilizada a polpa cítrica em substituição à silagem de milho é o possível efeito associativo entre os dois ingredientes.

Randel et al. (1975), citados por Wing (1982) estudaram a digestibilidade aparente da MS, PB, EB de dietas contendo níveis crescentes de substituição da silagem de milho por polpa cítrica (0, 33, 66 e 100\%) e verificaram efeito complementar entre a silagem de milho e a polpa cítrica na digestibilidade da MS e da EB (63,9; 69,6; 75,0; 73,7\% para MS, respectivamente, e 62,4; 69,1; 75,1; 74,9\% para EB, respectivamente, de acordo com os níveis de substituição). Os autores citaram ainda que o rendimento energético, expresso em kcal de energia digestível por kg de MS da silagem de milho, foi de 2.830 e o da polpa cítrica, de 3.468, enquanto, no nível de substituição de 33\%, o rendimento foi de 4.127 e no nível de $66 \%$, de 3.884 .

Com exceção dos animais alimentados com dieta sem polpa cítrica, o ganho de peso médio diário dos animais desta pesquisa foi superior ao encontrado por FurushoGarcia et al. (2004), que verificaram ganho de peso médio de 260 g/dia. Na comparação da conversão alimentar, no entanto, as médias foram melhores que as encontradas neste estudo (4,20 vs 4,33).

Os custos das dietas, em $\mathrm{R} \$ / \mathrm{kg}$ de MS, foram iguais para todos os níveis de polpa cítrica (Tabela 6). O preço por tonelada de PCUP foi de R $\$ 37,50$, incluindo o frete (50 km), enquanto o preço por tonelada de silagem de milho foi de $\mathrm{R} \$ 50,00$. O custo das dietas por ganho em $\mathrm{kg}$ de peso vivo (PV) foi semelhante para todos os tratamentos, o que sugere viabilidade econômica de substituição da silagem de milho por PCUP.

\section{Conclusões}

É possível substituir a silagem de milho por polpa cítrica úmida prensada até o nível de $75 \%$. O nível de $48 \%$ de substituição proporciona os melhores ganhos de peso. A utilização da polpa cítrica úmida prensada em substituição

Tabela 6 - Viabilidade econômica da substituição da silagem de milho por polpa cítrica em dietas para cordeiros em confinamento

\begin{tabular}{lrrr}
\hline Item & \multicolumn{3}{c}{ Nível de polpa cítrica (\%) } \\
\cline { 2 - 4 } & \multicolumn{1}{c}{0} & 25 & 50 \\
\hline Custo da ração (R\$/kg de MS) & 0,28 & 0,28 & 0,28 \\
IMS total (kg) & 322,67 & 379,01 & 344,91 \\
Custo total com ração (R\$) & 90,35 & 340,84 & 96,12 \\
Conversão alimentar (kg de MS/kg de ganho) & 4,45 & 4,44 & 4,26 \\
Custo/ganho (kg de PV) em R\$ & 1,25 & 1,19 & 1,19 \\
\hline
\end{tabular}


à silagem de milho depende de fatores econômicos e da disponibilidade do produto em cada região.

\section{Agradecimento}

À COROL Citrus, pelo fornecimento da polpa cítrica úmida prensada.

\section{Literatura Citada}

ALLEN, M.S. Effects of diet on short-term regulation of feed intake by lactating dairy cattle. Journal of Dairy Science, v.83, p.1598-1624, 2000.

ASHBELL, G.; DONAHAYE, E. Losses in orange peel silage. Agricultural Wastes, v.11, n.1, p.73-77, 1984.

BEN-GHEDALIA, D.; YOSEF, E.; MIRON, J. The effects of starchand pectin-rich diets on quantitative aspects of digestion in sheep. Animal Feed Science Technology, v.24, p.289-298, 1989.

CAMURÇA, D.A.; NEIVA, J.N.M.; PIMENTEL, J.C.M. et al. Desempenho produtivo de ovinos alimentados com dietas à base de feno de gramíneas tropicais. Revista Brasileira de Zootecnia, v.31, n.5, p.2113-2122, 2002.

DUTRA, A.R.; QUEIROZ, A.C.; PEREIRA, J.C. Efeitos dos níveis de fibra e das fontes de proteínas sobre o consumo e digestão dos nutrientes em novilhos. Revista Brasileira de Zootecnia, v.26, n.4, p.787-796, 1997.

FURUSHO-GARCIA, I.F.; PEREZ, J.R.O.; BONAGURIO, S. et al. Desempenho de cordeiros santa inês puros e cruzas santa inês com texel, ile de france e bergamácia. Revista Brasileira de Zootecnia, v.33, n.6, p.1591-1603, 2004.

GARCIA, I.F.F.; PEREZ, J.R.O.; TEIXEIRA, J.C. Desempenho de cordeiros texel $\mathrm{x}$ bergamácia, texel $\mathrm{x}$ santa inês e santa inês puros, terminados em confinamento, alimentados com casca de café como parte da dieta. Revista Brasileira de Zootecnia, v.29, n.2, p.564-572, 2000.

HENRIQUE, W.; LEME, P.R.; LANNA, D.P.D. et al. Substituição de amido por pectina em dietas com diferentes níveis de concentrado. 1. Desempenho animal e características de carcaça. Revista Brasileira de Zootecnia, v.27, n.6, p.1206-1211, 1998.

ÍTAVO, L.C.V.; SANTOS, G.T.; JOBIM, C.C. et al. Substituição da silagem de milho pela silagem do bagaço de laranja na alimentação de vacas leiteiras. consumo, produção e qualidade do leite. Revista Brasileira de Zootecnia, v.29, n.5, p.14981503, 2000a.

ÍTAVO, L.C.V.; SANTOS, G.T.; JOBIM, C.C. et al. Composição e digestibilidade aparente da silagem de bagaço de laranja. Revista Brasileira de Zootecnia, v.29, n.5, p.1485-1490, 2000 b.
KEARL, L.C. Nutrient requirements of ruminants in developing countries. Logan: Utah State University/ International Feedstuffs Institute, 1982. 381p.

MERTENS, D.R. Análise da fibra e sua utilização na avaliação de alimentos e formulação de rações. In: SIMPÓSIO INTERNACIONAL DE RUMINANTES, REUNIÃO ANUAL DA SOCIEDADE BRASILEIRA DE ZOOTECNIA, 29., 1992, Lavras. Anais... Lavras: Sociedade Brasileira de Zootecnia, 1992. p.188-219.

MERTENS, D.R. Regulation of forage intake. In: FAHEY J.R., G.C. (Eds.) Forage quality, evaluation and utilization. Madison: American Society of Agronomy, 1994. p.450-493.

NATIONAL RESEARCH COUNCIL - NRC. Nutrient requeriments of sheep. New York: National Academy Press, 1985. 99p.

PEREIRA, M.S.; MIZUBUTI, I.Y.; RIBEIRO, E.L.A. et al. Alterações químicas e perdas de matéria seca durante a ensilagem de polpa cítrica úmida prensada. In: REUNIÃO ANUAL DA SOCIEDADE BRASILEIRA DE ZOOTECNIA, 42., 2005 , Goiânia. Anais... Goiânia: Sociedade Brasileira de Zootecnia, [2005]. (CD-ROM).

PORCIONATO, M.A.F.; BERCHIELLI, T.T.; FRANCO et al. Digestibilidade, degradabilidade e concentração amoniacal no rúmen de bovinos alimentados com polpa cítrica peletizada normal ou queimada. Revista Brasileira de Zootecnia, v.33, n.1, p.258-266, 2004.

REIS, W.; JOBIM, C.C.; MACEDO, F.A.F. et al. Características de cordeiros alimentados com dietas contendo grãos de milho conservados em diferentes formas. Revista Brasileira de Zootecnia, v.30, n.4, p.1308-1315, 2001.

SILVA, D.J. Análise de alimentos (métodos químicos e biológicos) Viçosa, MG: Universidade Federal de Viçosa, 1990. 165p.

SILVA, A.G.; WANDERLEY, R.C.; PEDROSO, A.F. et al. Ruminal digestion kinetics of citrus peel. Animal Feed Science and Technology, v.68, n.3-4, p.247-257, 1997.

SNIFFEN, C.J.; O’CONNOR, J.D.; Van SOEST, P.J. A net carboydrate and protein sistem for evaluating cattle diets: II. Carbohydrate and protein availability. Journal of Animal Science, v.70, p.3562-3577, 1992.

STATISTICAL ANALYSES SYSTEM - SAS. SAS/STAT User's guide. Version 6, 4.ed. Cary: 1994. v.2, 846p.

Van SOEST, P.J. Nutritional ecology of the ruminant. Ithaca: Comstock Publication Association, 1994. 476p.

VERAS, R.M.L.; FERREIRA, M.A.; ARAÚJO, C.V. et al. Substituição do milho por farelo de palma forrageira em dietas de ovinos em crescimento. Desempenho. Revista Brasileira de Zootecnia, v.34, n.1, p.249-256, 2005.

WALDO, D.R. Symposium: forage utilization by the lactating cow. Effect of forage quality on intake and forage concentrate interactions. Journal of Dairy Science, v.69, p.617-631, 1986.

WING, J.M. Citrus feedstuffs for dairy cattle. Gainesville: University of Florida, 1982. 16p. (Florida Agriculture Experimental Station Bulletin, 829). 